\title{
Arduino Based Economic and Real Time Consumption Rate Computing
}

\author{
Shivesh Kumar, Sunil Kumar \\ Department of Mechanical Engineering, Sant Longowal Institute of Engineering and Technology, India
}

Received August 21, 2019; Revised September 25, 2019; Accepted October 10, 2019

Copyright $\bigcirc 2019$ by authors, all rights reserved. Authors agree that this article remains permanently open access under the terms of the Creative Commons Attribution License 4.0 International License

\begin{abstract}
Arduino based design of economic and real-time fuel consumption rate computing by digital mileage meter is intended to develop effective and economic mileage meter that can promptly exhibit fuel mileage of a vehicle and show it. This device can be added to augment the existing running automotive system also, which works on carburetor or for that matter fuel injection technology. The cumbersome task of computing and manually checking the mileage can be automated using this device. Infra-red and position sensors have been assembled with Atmega328P microcontroller and installed on the motorbike. The efficacy of the designed mileage meter is revealed by comparing results with literature and real condition.
\end{abstract}

Keywords Throttle Body Calibration, Mileage Meter, Engine, Real-time, Digital Mileage Meter

\section{Introduction}

Mileage indicator is a device which is used for indicating the fuel consumption rate of a vehicle [1]. In the current scenario fuel price is increasing day by day and pollution level increasing day by day by exhaust emitted by vehicle so there is a need to design such a system that helps in controlling these factors [2]. Therefore, system is a mechanism in which passenger vehicles display its fuel economy and it tries to connect fuel consumption of vehicle to measurable parameter as throttle position and speed of vehicle. To simulate the engine, it is better to divide the various component of engine to a subsystem. And for different subsystem, the various mathematical equation should be transformed to validate it correctly so that it can behave like a real engine. Most improvements have been made in the areas shown in the block diagram in Figure 1 for the last two or three decades.

There are two existing techniques that are based on performance, complexity, and cost of development. These techniques have some issues which are to be taken care of [3]. Alghadhi.et al [4] has considered the derivation of a mathematical model for the calculation of fuel consumption when applied to NEDC. Varghese [5] designed a fuel mileage indicator which can be mounted on any motorbike. Microcontroller has been used with PIC which takes information for fuel tank with the help of ultra sound sensor and stores data into a data acquisition system to generate mileage [6]. Analysis of throttle body flow is one of the important areas in calculating mileage [7,8]. To improve the mileage optimization of throttle assembly can be used for investigating using computational fluid dynamics (CFD) $[9,10,11]$. Simulation of a butterfly valve using a moving grid technique can be studied for torque, flow and discharge coefficients [12]. The display system has been improved by giving the feature which shows the distance to be traveled $[13,14]$. This is done on the bases of measuring the amount of liquid available in the tank and distance traveled $[15,16]$. There is a continuous requirement for the development of an economic and real-time fuel consumption rate using throttle position information.

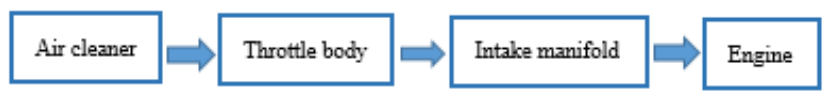

Figure 1. Schematic of the air intake system in SI engine

In the present work, an attempt has been made to design real-time mileage detection system using a microcontroller. The information of throttle value and wheel rotation has been collected through IR sensor and position sensor which is used to develop a program in Arduino software. This software is embedded in the microcontroller (Atmega328P) and information of real-time mileage is displayed on LCD. Further, results have been compared with the manual mileage measurement and compression has been done for different conditions. The results have shown the efficacy of the purposed design of mileage meter. 


\section{Proposed Solution}

The fuel mileage indicator has been fixed on cardboard setup as design warranted and it has been tested under different circumstances and situations. The tests were carried on an actual conventional vehicle and therefore are well-matched to be set up on any other vehicle with minor changes. The device worked efficiently under standard test conditions with displaying the value of mileage in different conditions. The system comprises of different type of sensors which are used to calibrate the position of throttle body from where the flow of fuel is calculated and another one is for measuring the velocity of the vehicle. The fuel mileage display will show the real-time mileage of the vehicle. The reading will be displayed at some standard speed at which the throttle position and the mileage is shown. Figure 2 shows the design of system hardware which consists of microcontroller (Atmega328P) ADC,16*2 display, position sensor, IR sensor. Initially, the microcontroller is initialized and with the help of position sensor for throttle position and speed measurement through IR sensor.

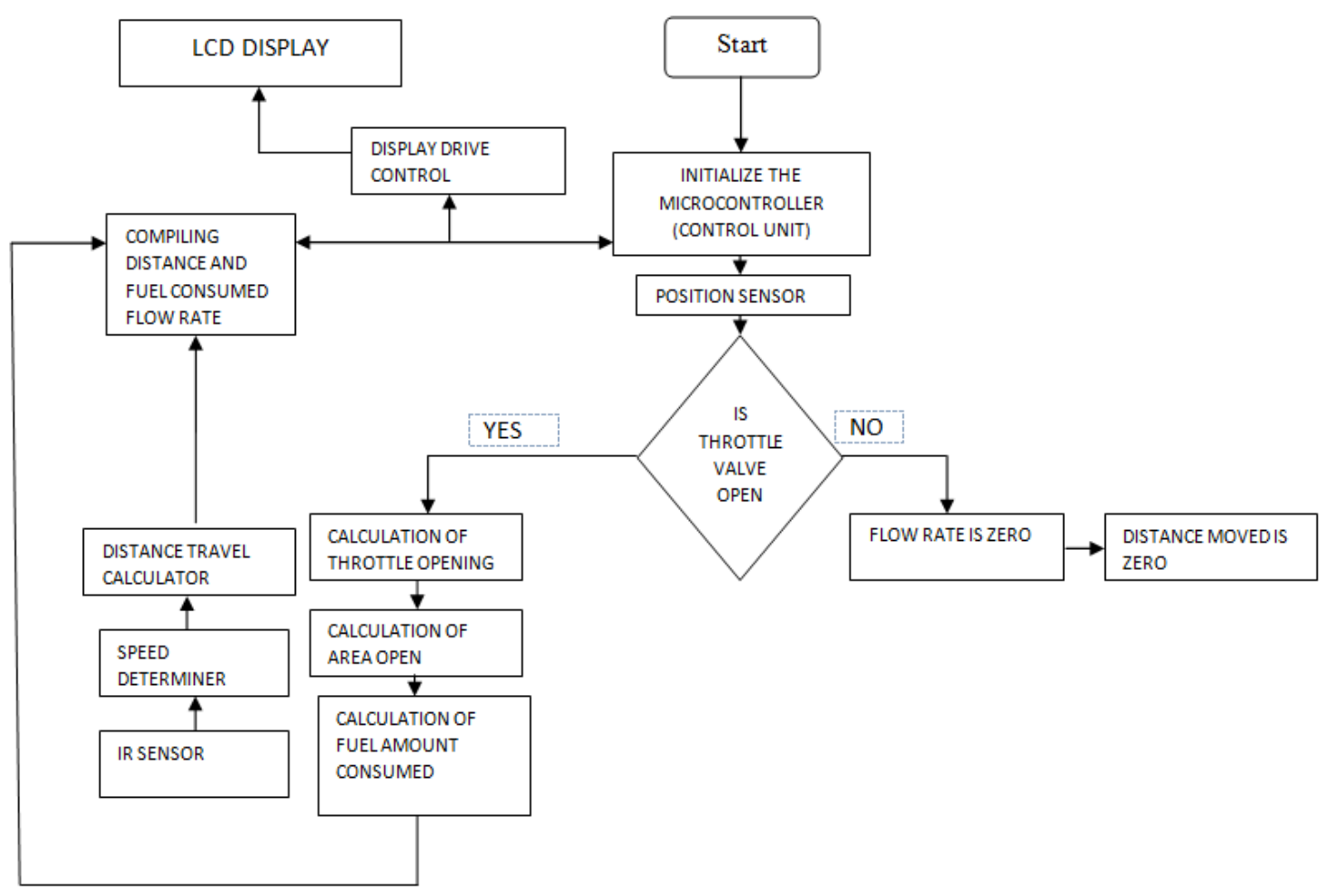

Figure 2. Flow diagram representations design of system hardware

\section{Components}

The different component that are used in design of the mileage consumption rate computing system are microcontroller, position sensor, IR sensor and LCD, which are discussed in this section.

\subsection{Microcontroller}

Atmega328P microcontroller has been used in the present work. It contains fourteen inputs and output pinout which six are for PWM o/p, six for analog input $16 \mathrm{MHz}$ quartz crystals, one each for USB, power jack, ICSP and reset button. It provided all the required functions and can be connected to a computer through USB cable. It is used for programming the interface of two input devices to out devices LCD.

\subsection{Position Sensor}

Instrument that use to measure a position is known as potentiometer it is a voltage divider used for measuring voltage (i.e. electric potential). Potentiometers are used to control electric device and their various application is audio equipment volume control. The mechanism that used to operate as a potentiometer can also be used as a position transducer for example in joystick. It is used for measuring the throttle angle which is further sent to a microcontroller. 


\subsection{IR Sensor}

An Infrared sensor has been used is an electronic instrument for measuring attributes through emitting and/or detecting IR. These are efficient in measuring heat and motion. LED has been used for emitting light with wavelength and intensity as per the IR. When proximity occurs, light from the LED reflects and falls on a light sensor, resulting in jumping of intensity. This signal is noted and sends to the controller. In present work, IR has been used to measure the rotation counts of the wheel and send its information to the microcontroller.

\subsection{LCD}

The LCD used is of high quality sixteen characters displaced in two-line display module HD44780. It has inbuilt equivalent LCD Controller/driver with 4-bit or 8-bit MPU Interface. This displace system is compatible with the Atmega 328P microcontroller.

The components have been assembled on the bases of the block diagram shown in Figure 3. Information form position and IR sensors is fed to the controller and calculated mileage is shown in the LCD system.

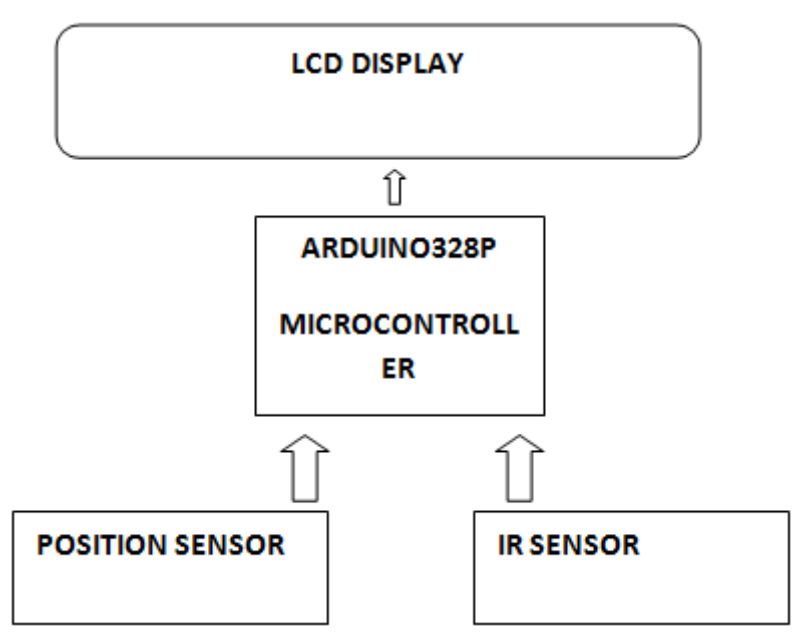

Figure 3. Block diagram (assembling of component)

The assembly has been first done on the ISIS proteus software as shown in Figure 4 and programming has been done in Arduino software. On board hardware assembles after embedding the program is shown in Figure 5 (a) and Figure 5 (b) shows the detail of assembly of hardware (mileage meter) on Honda CD100.
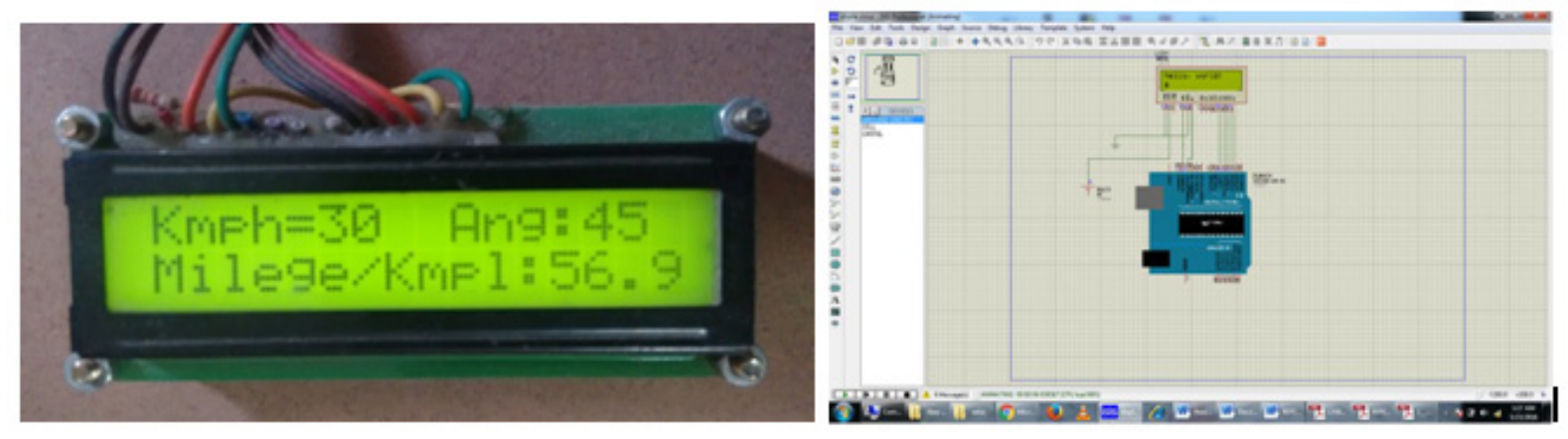

Figure 4. LCD display and its assembly on ISIS proteus software

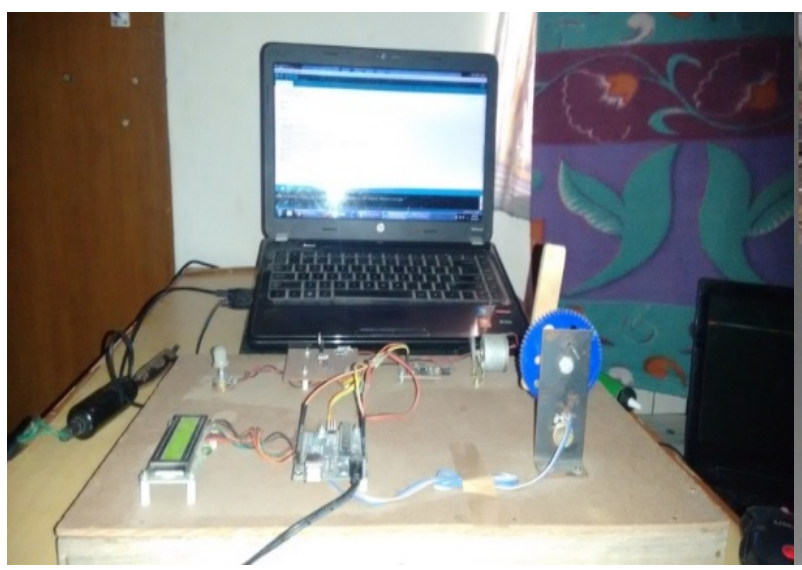

a)

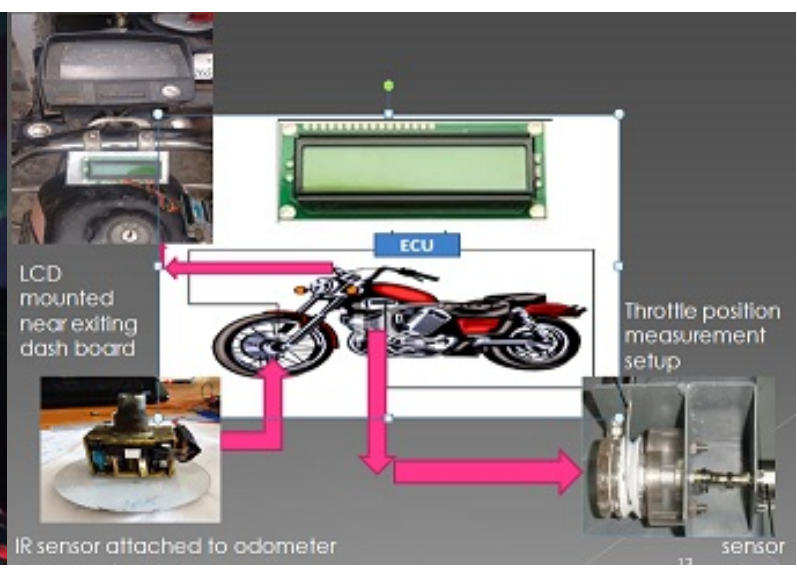

b)

Figure 5. Testing of display by using Arduino 


\section{Results and Discussions}

The designed system has been applied for various speed and throttle position to examine mileage of the vehicle and displayed it on an LCD screen. All programming and analog to digital conversion of a related parameter is performing by software Arduino. The result obtains with the help of LCD are shown in Table 1.

Table 1. Relation between throttle position and mileage at different speed standard

\begin{tabular}{|c|c|c|}
\hline Speed $(\mathrm{km} / \mathrm{h})$ & Throttle position & Mileage $\left(\mathrm{kmpl}^{*}\right)$ \\
\hline 10 & 17 & 50.2 \\
\hline 20 & 32 & 53.4 \\
\hline 30 & 45 & 56.9 \\
\hline 40 & 58 & 58.9 \\
\hline 53 & 82 & 55.2 \\
\hline 60 & 94.6 & 54.5 \\
\hline 74 & 122.1 & 49.1 \\
\hline
\end{tabular}

Figure 6 shows the throttle position concerning for to speed. It is observed that speed increases as throttle opening increases. From Figure 7 it is observed that with the increase in throttle position mileage get increases up to 58 degrees i.e. optimum speed level and after that, it goes on the decrease. The trend indicates that the total airflow rate through the throttle body increases with an increase in throttle opening. This is mainly due to the reduced restriction by the throttle valve when it opens more and due to increased engine suction, which draws additional air.

*Kilometer per liter

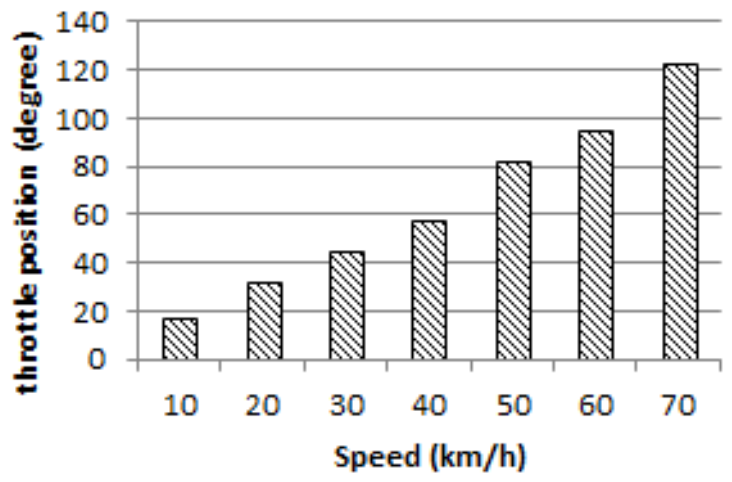

Figure 6. Plot of throttle position vs speed

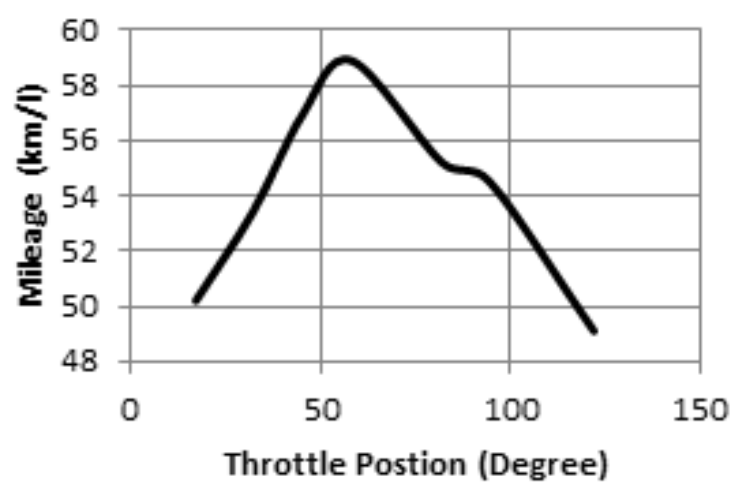

Figure 7. Plot mileage vs throttle position

The designed mileage meter has been attached with Hero Honda CD100 and results have been obtained for single and double person load respectively. The obtained results have been further compared with the data from the research paper [5] and data observed at the real condition. Mileage has been obtained for three speeds $(20 \mathrm{~km} / \mathrm{h}, 40 \mathrm{~km} / \mathrm{h}$ and $60 \mathrm{~km} / \mathrm{h}$ ). The readings noted for this study are observed and plotted on a single graph for a single person and double person load as shown in Figures 8 and 9. These figures comparisons the values obtained from the designed module, research paper, and real condition. It is observed that for all the three conditions maximum mileage is at $40 \mathrm{~km} / \mathrm{h}$. Results obtained by the designed module are close to the real condition as compare to the results of the research paper.

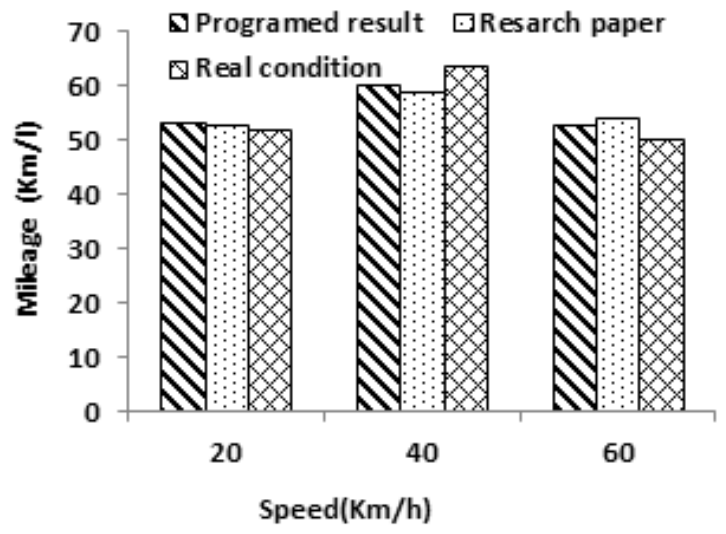

Figure 8. Results for single person load 


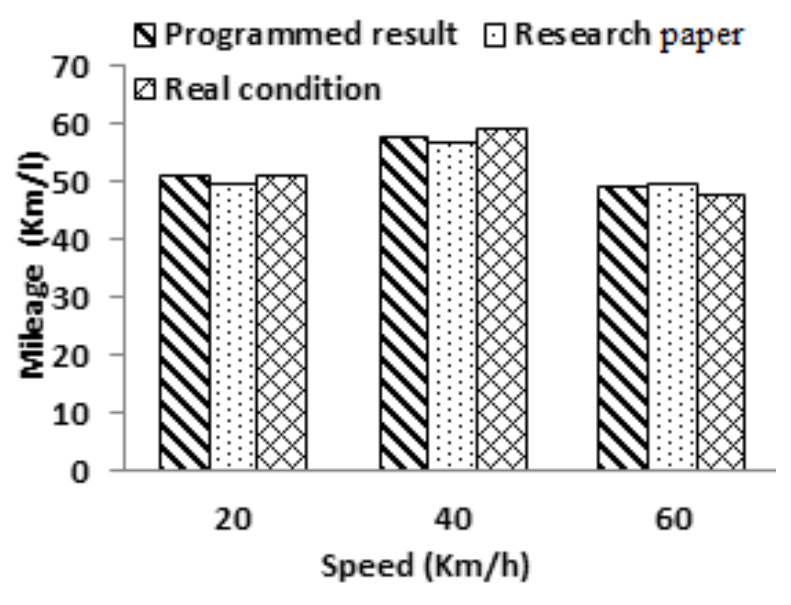

Figure 9. Results for two-person load

\section{Conclusions}

A decision-making system has been designed to detect the mileage of the vehicle at throttle position which helps the driver to understand the maintenance level of the vehicle. The more efficient and reliable sensing technology to measure the mileage of the vehicle is to use throttle body calibration by using a position sensor at the accelerator paddle and an IR sensing device at the wheel to measure its velocity. It is easy and cheapest way to calibrate the vehicle mileage. The real-time mileage calculation has been taken by running the model by using real condition parameters and using the simulated result of throttle body calibration. Program based on Arduino software developed on bases of information from $I R$ and position sensor has been embedded on Atmega 328P microcontroller. The designed mileage meter has been implemented on Hero Honda CD 100 with a single- and double-person load. The results have compared with the reference and real condition. It has been observed that results are closer to real conditions as compared to reference values. Optimum speed level is between 35 to $45 \mathrm{kmph}$ in which vehicle provides the maximum mileage.

\section{REFERENCES}

[1] Farrell G. Butler, "Gasoline Mileage Indicator System," US Patent 3958453, May 1976”.

[2] Kosuge, et al, "Method and apparatus for indicating mileage corresponding to remaining fuel for vehicles," US Patent 4400779, August 1983.

[3] Divakar V. (2014), "International Journal of Advanced Research in Computer Engineering \& Technology (IJARCET) Volume 3 Issue 1,” ISSN: 2278 - 1323.

[4] M. Alghadhi , A. Ball, L. Kollar, R. Mishra and T. Asim, "Fuel Consumption Tabulation in Laboratory Conditions,"
In: International Research Conference on Engineering, Science and Management, (IRCESM) 4-5 June, Traders Hotel Dubai: UAE, pp.170-180, 2014.

[5] Varghese, J. C., Balachandran B.E. (2013) International Journal of Innovative Technology and Exploring Engineering (IJITEE) ISSN: 2278-3075, Volume-2, Issue-5.

[6] Reza khan,Sadeque.,Ferdousi,Arifa., and Reza,S.K. (2013) Real time generator fuel level measurement meter embedded with ultrasound sensor and data acquisition system Journal of Automation and Control Engineering vol. 1, no.4.343-348.

[7] Alsemgeest R, Shaw C T, Richardson, S H \& Pierson S H SAE Paper2000-01-0659, (2000) DOI: 10.4271/2000-01-0 659.

[8] Ross P, Alain K, \& Hong S, SAE Paper 2000-01-0571, (2000) DOI: 10.4271/2001-01-0571.

[9] J Suresh Kumar, V Ganesan, J M Mallikarjuna\& S Govindarajan. Indian Journal of Engineering \& Materials Sciences Vol. 20, October 2013, pp. 350-360.

[10] Chen J \& Chen G SAE Paper 951057, 1995, (2000) DOI: $10.4271 / 951057$.

[11] Diego H SAE Paper2006-32-0113,(2006) DOI: 10.4271/ 2006-32-0113.

[12] Wang I, X Song \& Y Park, ProcIMech E, Part G Process, Eng J MechEngSci, vol 224, DOI: 10.1243/09544089 MES 1679.

[13] Avinashkumar, U. Singaravelan, T. V. Premkumar, K. Gnanaprakesh, IOSR Journal of Mechanical and Civil Engineering (IOSR-JMCE) e-ISSN: 2278-1684,p-ISSN : 2320-334X, Volume 11, Issue 2 Ver. III (Mar- Apr. 2014), PP 80-84.

[14] Ti-Ho Wanga, Ming-ChihLua and Chen-Chien Hsu, (2009), "Liquid-level measurement using a single digital camera," Elsevier, Measurement, 42(4): 604-610.

[15] Deep Gupta, Brajesh Kr. Singh and Kuldeep Panwar, "A Prototyping Model for Fuel Level Detector and Optimizer" page no 226- 229 - African Journal of Basic \& Applied Sciences 4 (6): 226-229, 2012 ISSN 2079-2034.

[16] Umesh P. Hade, Prof. A. R. Suryawanshi "International Journal Of Engineering, Education And Technology (ARDIJEET) ISSN 2320-883X, Volume 3 Issue2, 01/04/2015. 